\title{
Used Vehicles Survival Rates and Their Impacts on Urban Air Quality of Addis Ababa, Ethiopia
}

\author{
Yilak A Kebede \\ Lantern Institute of Data Science
}

\begin{abstract}
The longevity of imported used vehicle determines urban outdoor air pollution and affects government's regulatory policy measures to balance the benefit of used vehicle usage and its negative externalities. This paper estimates the life expectancy of vehicles in Ethiopia for a maximum of 30 years. The study used four different models to determine the total vehicle stock, survival rate and scrap rate of vehicles at different age and the total emission respectively. The models support different estimation, where there is difficulty to find actual data related to scrap vehicles. The total emission calculation serves policy makers to make a learned and informed decision that improves urban air quality.
\end{abstract}

Key words: Survival rate, scrap rate, urban air quality, vehicle stock, total emission

\section{INTRODUCTION}

Transportation is one of the single most polluting emission sources in African cities and motor-traffic has a major share in the total outdoor air pollution. Air pollutants such as particulate matter (PM) are affecting the public health of developing nations and some studies indicate that environmental pollution has become one of the major sources of health risk throughout African cities (UNEP, 2005). The immediate risks are generally higher in developing countries due to weak environmental legislation and lack of technologies to control air pollution (David, 2003). Especially, concerns arise when the majority of vehicle fleets are old.

The air pollution costs peoples' health and incurs billions of dollars in medical bills and working days lost. According WHO (2016) report, air pollution has become a growing concern in the past few years and kills around 3 million people related to ambient air pollution. This report also indicates that pedestrians are the major victim of ambient air pollution caused by motorized transport in developing cities.

Total emission from vehicles is directly correlated with service age. Alen Greenspan and Cohen (1999) have put forward their empirical preposition that very few vehicles are scrapped during the first three to four years of life. During this period, most scrappage presumably results from accidents; in later years, scrappage may result from an economic decision by the owner to replace an increasingly unreliable vehicle with a more reliable alternative.

\section{VEHICLE CLASSIFICATION IN ETHIOPIA}

Generally, vehicle ownership levels depend on the national GDP/Capita; and compared with other regions, sub-Saharan African countries have the lowest motorization level. Ethiopian vehicle ownership may be categorized into five broad groups; private, public transport, commercial, governmental, international / nongovernmental organizations (shown in figure 1).

Compared with Kenya and Tanzania by average vehicle age, Ethiopia has an older vehicle fleet.. From the September 2009 UNEP report, the average age of Tanzania's vehicle population was 15 years. Similar average ages have been reported in Uganda (>13 years), Ethiopia (20 years) and Kenya (13 years). (UNEP, September 09). Light and heavy trucks usually stay longer than passenger vehicles. 
Figure 1 Ethiopian Vehicle Classification, Average vehicle -kilometre and age structure

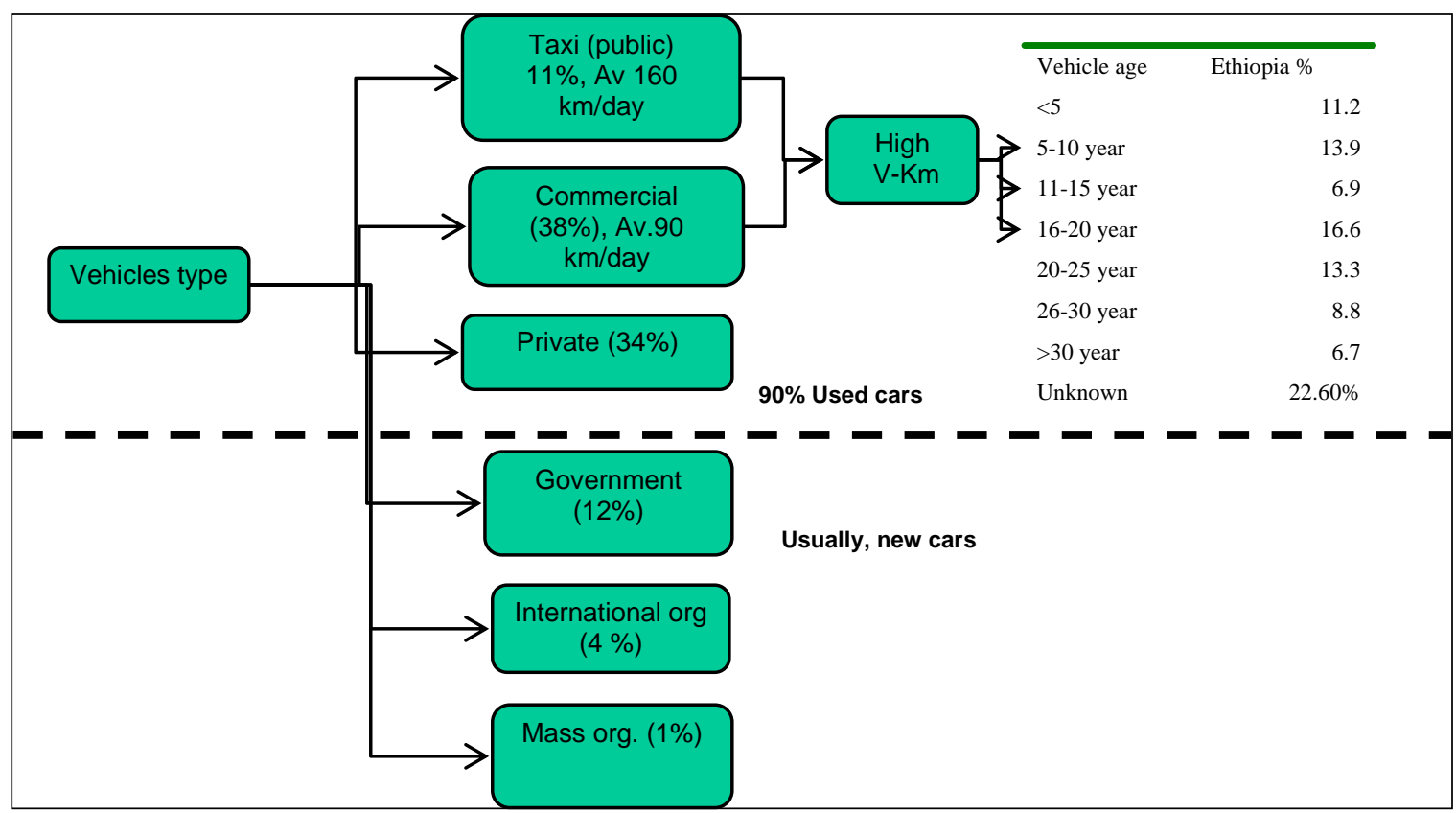

\section{VEHICLES SURVIVAL RATE IN ETHIOPIA}

Vehicle survival rate or longevity research has two main streams; the first deals with the estimation of mathematical survival or age-specific scrap rate functions, and the second deals with examining the determinants of scrap rates (Feeney, 1988). Different literature agree that there is considerable uncertainty on determining survival rates of motor vehicles, as it is difficult to find consistent data on different vehicles model and years of services. This uncertainty is worse in developing countries as the survival rate varies considerably and may be longer than anticipated. Usually the survival rate differs from country to country, based on the country's economic strength that mainly determines the road condition as well as the fuel quality. In addition to these factors, being a used vehicle, since it is imported, makes it difficult to calculate the survival rate of vehicle population in developing countries.

In general, scrappage (or scrap rates?) of vehicles is correlated with the cost of maintenance and fuel consumption. Old models of vehicles consume more fuel and their market value is reduced when the fuel price increases. Availability of spare parts is also a determining factor regarding the survival rate of vehicles. Some research shows that the average vehicle-kilometre travelled is around $18000 \mathrm{~km} /$ year for private vehicles and for commercial vehicles is $55000 \mathrm{~km} / \mathrm{year}^{1}$. On the other hand, a survey conducted in the Kenyan vehicle inspection center shows some vehicles have reached $900000 \mathrm{~km}$ mileage for private and 999000 for commercial; which could be exemplary to show the high mileage in developing countries.

\footnotetext{
${ }^{1}$ Federal Highway Administration of United States,
} June 2015

\section{Literature Review on Survival Rate Models}

Various studies have been conducted to predict vehicle stock of individual countries .De Jong et. al, (2004) developed a model called "Aggregate Time Series Models" that predicts the vehicle ownership based on different parameters such as national GDP Per-capita income. Greenspan and Cohen (1999) have also developed a framework to forecast aggregate sales of new motor vehicles based on the vehicle stock and scrap rate. Their model took account of the following variables; demographic trends, economic status, consumer preferences, expected new vehicle prices, repair costs, and vehicle retirements. Hirota (2007) has developed a model that assists to predict the vehicle stock from the past trends. That research focused on factors such as rapid economic growth, urbanization, and motorization of four ASEAN countries, Indonesia, Malaysia, the Philippines, and Thailand.

Studies such as Hayashi et. al (2001) use a cohort model to determine the survival rate of vehicles to analyze Japan's vehicle choice trends due on environmental taxation. Usually, a cohort model is used to determine a short term estimation; particularly for a country that has shown significant growth rate in car stock. This can be done by using the survival rate estimation based on well recorded data on new car introduction and scrapped vehicles. However, developing countries such as Ethiopia and other African nations, don't have well recorded data for their scrapped vehicles. The majority of newly introduced used automobiles also do not have vehicle history, which makes the vehicle stock estimation more difficult and complicated. Furthermore, any existing data are generally not meant to examine transport research questions and are rather simply for taxation and 
administration purposes (Hirota, 2007).

Survival rate estimation is necessary to estimate passenger car ownership in the country as well as the total emission from vehicles that help to analyze and formulate policies in relation to transportation, urban environment, and macroeconomic policies (Yan et. al, 2011). Researchers in developing countries are often forced to employ simplified methods as they usually face data shortage and inconsistency. Table 1 shows some of published vehicle scrappage models that determine survival rate. $R$ is retirement rate, $\mathrm{Su}$ is survival rate, $\mathrm{t}$ is lifetime years (based on Yan et.al, 2011).

Table 1. Models literature summery

\begin{tabular}{|l|l|l|}
\hline Citation & Equation & Key parameters \\
\hline Walker, 1968, logistic & $R(s)=\frac{1}{B+\exp \left[\alpha\left(1-s / L_{50}\right)\right]}$ & $\begin{array}{l}\text { B tail representing old vehicles, } \\
\alpha \text { shape factor, } L_{50} \text { median } \\
\text { life time }\end{array}$ \\
\hline Zacharidis et.al 1995 & $S u(s)=\exp \left[\left(\frac{s-b}{t}\right)^{b}\right]$ & $\begin{array}{l}\text { b, failure steepness, t } \\
\text { characteristic service life, }\end{array}$ \\
\hline $\begin{array}{l}\text { Modified Weibull US, } \\
\text { EPA 2005 }\end{array}$ & $S u(s)=\frac{1}{\sqrt{2}} \exp \left[-\left(\frac{s-s 0}{2 \sigma^{2}}\right)^{2}\right.$ & $\begin{array}{l}\text { s0, age at onset of significant } \\
\text { retirement } \sigma, \quad \text { steepness of } \\
\text { change }\end{array}$ \\
\hline Hiroto, 2007 & $P_{t}=a^{t /(t-m)-}$ & $\begin{array}{l}\text { t: vehicle age at the year M: } \\
\text { maximum age (M=30) } \\
a: \text { constant (elasticity of scrap } \\
\text { in terms of sales in the year }) \\
\text { p: survival rate p }(0)=1, \mathrm{P}(\mathrm{m})=0\end{array}$ \\
\hline Hayashi et.al (2001) & $L_{a, t}^{k}=C_{a, t}^{k} / C_{(a+1),(t+1)}^{k}$ & \begin{tabular}{l} 
age $a$ and class $k$ in the year $t$ \\
\hline
\end{tabular}
\end{tabular}

In most developing countries where Hirota's (2007) cohort model use to analyze vehicle emission by vehicle stock with poor recording on scrapped vehicle. And in this condition, it is difficult to implement directly the equation of Hayashi et. al (2001) that need year-based data. However, Greenspan and Cohen (1999; in Hiroto, 2007), have introduced a method to determine survival rate with variables that represent the physical deterioration and vehicle market value. This model is helpful to estimate the survival rate of vehicle in countries with poor recording tradition.

Due to a relatively high road accident rate in Africa, scrap estimation is more complicated. Greenspan and Cohen model determine the survival rate from the elasticity of new car sales and scrap. Generally, scrap could be calculated as follows:

Scrap $=$ car stock of previous year + new cars sale of present year-car stock of present year

In most African countries, including Ethiopia, the government does not decide when the vehicle is to be scrapped. It is individuals or vehicle sales agent that make the choice; by weighing the benefit between being scrapped and extended maintenance expenses. A focal discussion with Ethiopian local dealers showed that new vehicle price and repairing/maintenance cost plays a key role in the owners' scrap decision.

2. Methodology

Because of poor scrap data recording in Ethiopia, this research used a set of models to predict the country vehicle stock and scrap rates, and then total air emission in a time series. The models used four important steps to calculate the total emission as shown in the Figure 2.

Figure 2 Steps flow to calculate the total emission of vehicles stock

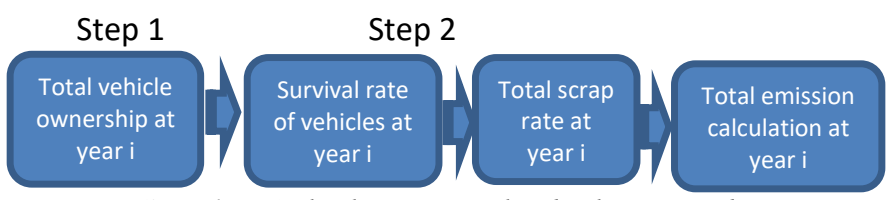

Step 1: - Calculating Total vehicle ownership at year $i$

Aggregate Time Series Models relate different economic parameters, which could be found from statistical records to estimate the overall car ownership. Comparing to other models, this model requires less detailed data. Thus, due to inadequate Ethiopian data recording system, this model is used to calculate total vehicle population. 
The total passenger vehicle stock can be estimated by using Gompertz function (Used by M.Wang et.al, 2006) that may be expressed as

$$
V_{t}=V_{s} e^{\alpha e^{\beta E F_{t}}}
$$

Where:

$V \quad$-Vehicle ownership in year i (vehicles per 1,000);

$V_{s}$-Ultimate saturation level of vehicle ownership (vehicles per 1000 people);

$E F_{i, t}$ - Represents the economic factor (per capita GDP) of country $i$ in year $t$;

$\alpha$ and $\beta$ - Two negative parameters that determine the shape of the S-curve. The increase of $\alpha$ and $\beta$ would lead to a steep $\mathrm{S}$-shape curve against the economic factors.

The ultimate saturation level could be based on the existing economic performance of countries and previous trends seen in other countries. There are three typical vehicle ownership trends in the last century; the North American growth pattern that grows faster with the increase of per-capita GDP and stopped at a level of 800 vehicles per 1000 people. The second is European which the vehicle ownership growth shows comparatively slower relationship with the total per capita GDP and reaches to the level of 600 vehicles per 1000 people. The third is Japan's vehicle ownership trend that reaches 550 vehicles per 1000 people.

To use the Gompertz function ${ }^{2}$, knowing the saturation level of vehicle ownership is important. This paper uses Button et. al (1993) ranges for low income countries vehicle saturation of 300-450 cars/1000 people. Thus, given the current economic situation and vehicle ownership of Ethiopia, taking the lower value of 300 vehicles/ 1000 people is reasonable.

\section{Model 2: Survival rate of vehicles at year $i$}

To determine the scrap or retirement rate of vehicle stock, it is necessary to determine the survival rate. Different studies have estimated survival rate based on different parameters explained in Table 1.

However, Okamoto's model is important to estimate survival rates based on the car stock, the maximum service age of a passenger vehicle. This research assumes 30 years as a maximum service age, given most research shows service ages ranging between 15 to 35 years. Due to data limitations, the authors chose the logistic function of Hiroto's model (2007), which is based on Greenspan and Cohen (1999?) estimation models, to determine the survival rate and scrap rate of Ethiopian vehicle stock. In Greenspan \& Cohen (1999) the main concept revolves around determining the survival rate of vehicle stock by the elasticity of the new sales unit.

2 Gompertz function is a type of mathematical model for a time series, where growth is slowest at the start and end of a time period.
Elasticity of scrap is assumed to be constant in terms of sales in the year $\mathrm{t}$

$$
P_{t}=a^{t /(t-m)}
$$

t: vehicle age at the year (to compare with the data available)

M: maximum length of service year for passenger vehicle $(\mathrm{M}=30)$

$a$ : constant ( elasticity of scrap in terms of sales in the year )

$\mathrm{p}$ : survival rate $\mathrm{p}(0)=1, \mathrm{P}(\mathrm{M})=0$

In order to estimate $\mathrm{M}$ and $a$ in the above equation is converted in to Log form.

An average value $\overline{\bar{A}}$ (equation 3 ) is supposed to be equal to the fixed value of $\log a$ and $\mathrm{b}$ and an average value of $\overline{\bar{M}}$ (equation 4 ) is supposed to be equal to the fixed value of $\mathrm{M}$.

Therefore, the simultaneous equation of (equation 3 and 4) estimate $\log a$ and M. The author used simultaneous equations to get the variable that expressed in the form of a single variable.

$$
\begin{aligned}
& \overline{\bar{A}}=\frac{1}{n} \sum_{t} \log p(t)-\overline{\bar{M}} \frac{1}{n} \sum_{t}\left(\frac{\log p(t)}{t}\right) \\
& \overline{\bar{M}}=\frac{1}{n} \sum_{t} t-\overline{\bar{A}} \frac{1}{n} \sum_{t}\left(\frac{t}{\log p(t)}\right)
\end{aligned}
$$

$\overline{\bar{A}}$ : Average value of various result of $\log a$ (elasticity varies by country and by year)

$\overline{\bar{M}}$ : Average value of various results of $\mathrm{M}$ (maximum length of service year for passenger vehicle). According to a sample survey at Kenyan vehicle inspection center on 247 vehicles, most of the commercial trucks and big public transport have longer service year and mileage coverage.

$\mathrm{n}$ : the number of new cars sales ( in Ethiopian or other developing case, it could be considered relatively new vehicles with service age of 0-5 years).

\section{Model 3: Retirement's (scrap) rates,}

Scrap or permanent retirement rate provides a relationship of vehicles either in the form of a fraction or fraction of vehicles surviving at specific age $t$. Therefore the retirement rate $R$ during the time period of $\Delta t$ that begin at time $\mathrm{t}$ can be determined from the survival rate (Su) ( Yan et.al, 2011):

$$
R(t, \Delta t)=1-\left(\frac{S u(t+\Delta t)}{S u(t)}\right)
$$


There are many factors that affect the vehicle retirement rates both temporarily and permanently, such as vehicle age, measure of service, economic considerations, fuel price, emission test requirement, availability of spare parts, etc. Greenspan and Cohen (1999) relate that "scrap is favoured when the cost of repairs is relatively high in the price of new cars". Greenspan and Cohen (1999) also mention that scrap could have an inverse relationship with the price of gasoline as vehicles are less driven in this condition.

\section{Model 4: Total emission calculation at year $i$}

Vehicle emission rate has a direct relationship with the vehicle service age. Model of vehicles doesn't represent that the vehicle is old or new, rather the service age explains the degradation of engine performance and air pollution equipments. The total stock of vehicles could be calculated by subtracting the scrapped from the total estimated vehicles.

= existing vehicles by age+ imported vehicles by agescraped (either by age or by accident) (6)

Based on the total vehicle stock estimation at time $t$, the Yan et.al (2011) total emission model could be employed to calculate the total emission $E(t)$ in $g$.

$E(t)=\sum_{i} \sum_{s} V_{i, s}(t) F_{i, s} E F_{i, s}$
Where $\mathrm{F}_{\mathrm{i}, \mathrm{s}}$ are the fuel consumption ( in $\mathrm{kg}$ Vehicle 1) and emission factor (in $\mathrm{gkg}^{-1}$ ) for vehicle of type I and age $s$.

Both of the equations require an estimation of new vehicles and fuel consumption, however, in the Ethiopian case, we can consider that close to $95 \%$ of private vehicles are used with fuel consumption of an average 10 kilometer/ liter.

\section{Results and Analysis}

National GDP per capita is usually used as an economic parameter to estimate national vehicle ownership; however it might not reflect the reality in developing countries. Thus, this research narrows down the focus on Addis Ababa city's GDP rather than the country's total GDP. Besides, high income per capita disparity among consumers distorts the real capacity of consumers to buy new cars (including imported used vehicles). According to UN data, the GDP per capita of Ethiopia has increased from 116.9 dollars in the year 2000 to 318.7 dollars in the year 2008. Figure 3 shows the GDP per capita growth and vehicle ownership have strong co-relation in Ethiopia's case.

Figure 3-Per-capita GDP and vehicle ownership rate from 2001/02- 2010

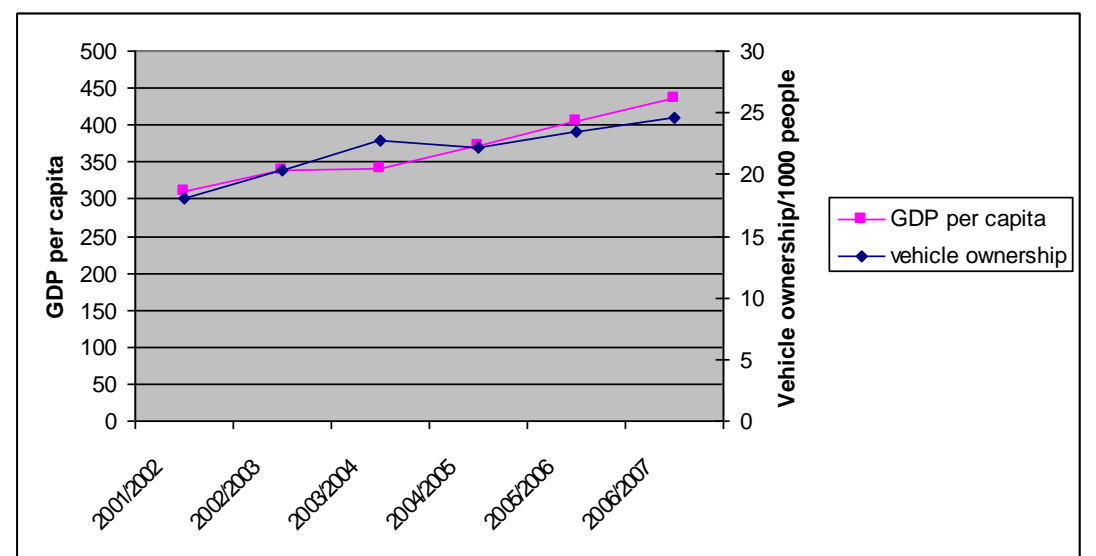


Figure 4. Vehicle stock estimation till 2001-2015 based on Compertz's function

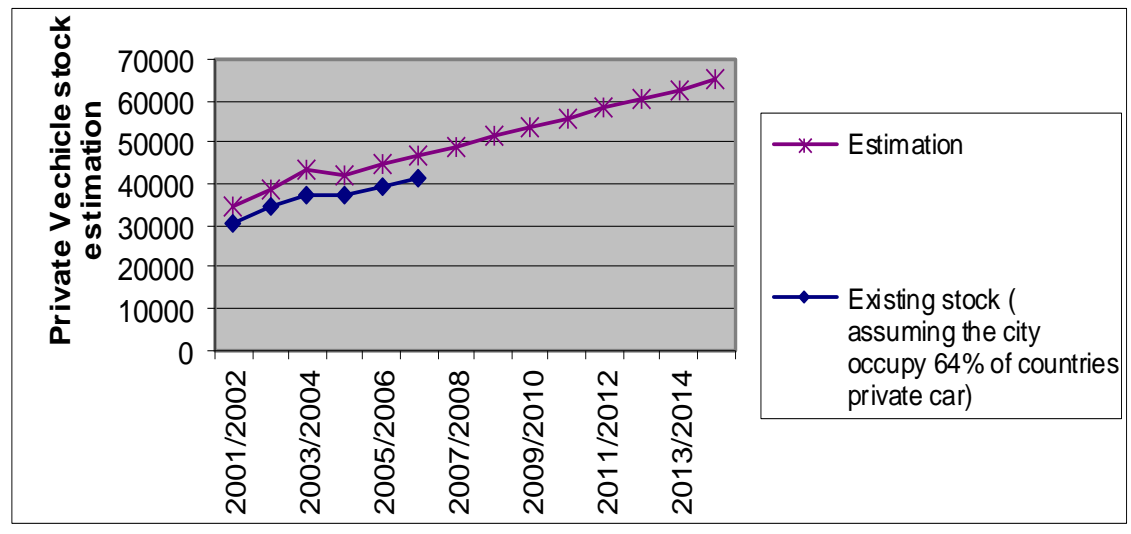

Based on GDP per capita and private car ownership growth rate, the total vehicle stock of the city at different years is calculated as shown on Figure 4. The total vehicle stock is estimated assuming that the rate of average GDP/capita growth and the average vehicle ownership growth rate between 2006 and 2009 stay the same till 2015.

By using the logistic function equation (2), it is possible to calculate the survival rate vehicles at different age. Vehicles are usually considered as fixed assets in Ethiopia and this extends the vehicle life expectancy further to protect the asset value. Usually, vehicles survive 20-40 years in Ethiopia but for this study 30 years is considered as shown in Figure 5. This wider range of survival rates have its own impact on the total air pollution. Besides, lack of regular maintenance and high vehicle-kilometres travelled (private automobile is more than 20,000 km-year for private and $62,000 \mathrm{~km}$-year for public) further exaggerates its environmental impact.

Figure 5. Survival rate percentages for 1000-1300 cc private vehicles

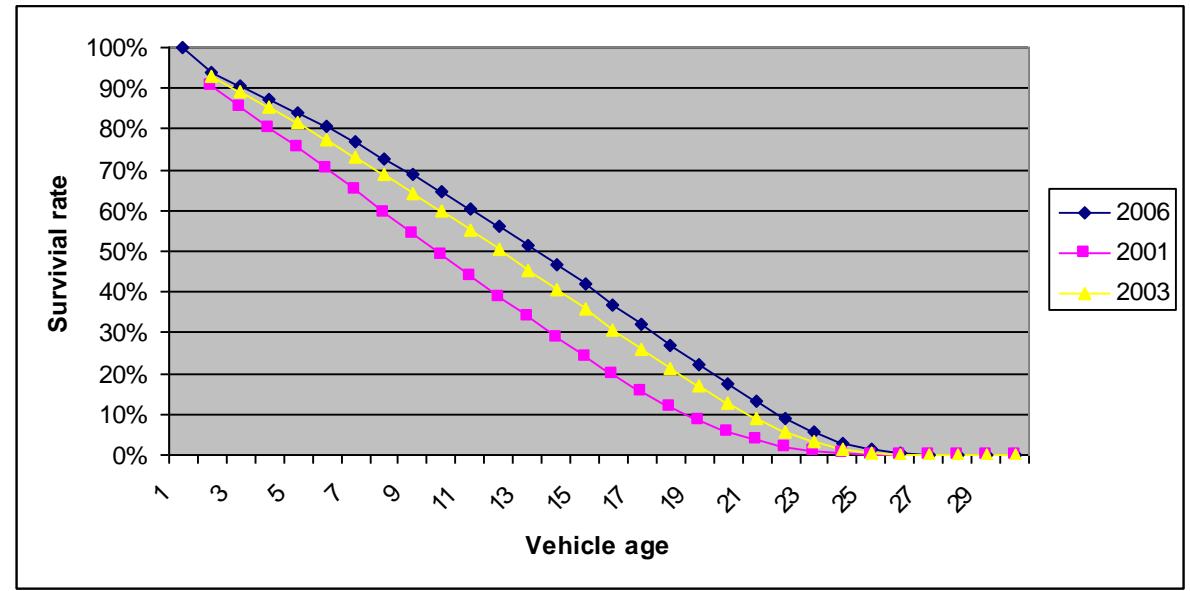


Figure 6. Comparisons of vehicles survival rates in different countries (Wang et.al, 2006)

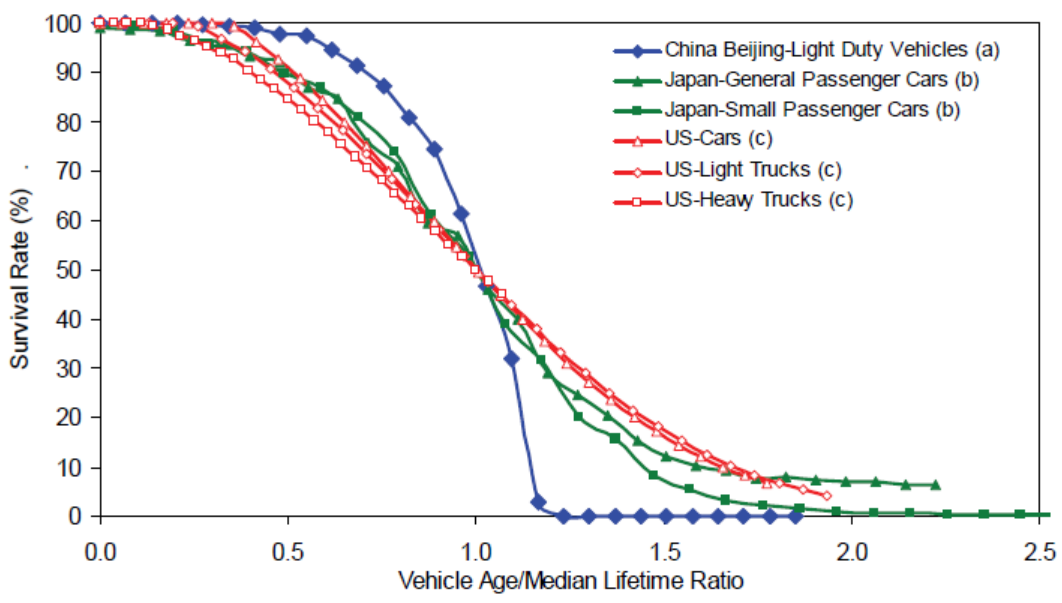

(B) Survival Rate vs. Vehicle Age/Median Lifetime

Figure 7 . Vehicle scrap rate at time $t$

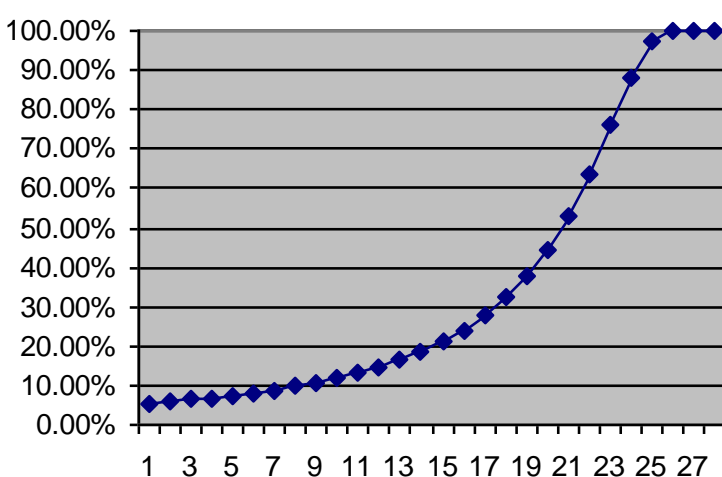

- scrappage percentile

Figure 6 shows that China's survival rate swiftly changed because of regulation and have shown positive results in emission reduction. However, further consideration should be taken to minimize negative externalities of the emission reduction policy on economic and social wellbeing. Thus, it is advisable for developing countries to take a step by step protection and restriction on the survival rate of vehicle through different policy instruments such as taxation and inspection. The higher the survival rates of old vehicles, the greater the impact on overall public health of the city dwellers and pedestrians (accounts to $54 \%$ of totally mobility ${ }^{3}$ ) are affected outdoor air pollution.

The scrap rate could be calculated by using equation (5). The scrap rate differs from country to country and on a yearly bases, however ,this study uses an average survival rate constant to calculate the scrap rate at time $t$, and the result is shown on Figure 7 (for the sake of simplicity up to 15 years of service is considered).

Therefore, as Figure 8 shows, the total vehicle stock in the country by age group is calculated based on the three models and the total stock equation expressed in equation

3 World Bank Project Information Document on Addis Ababa Transport (2016)
(6). The scrapped vehicle data is difficult to find in Ethiopia, hence, this research used only registered and licensed vehicles. Besides, the research ignored vehicles scrapped as a result of an accident, as the opportunity for the damaged car to be overhauled and reuse is very high.

By using equation (7) it is possible to calculate the total emission at different years. However, the emission factor has to be adjusted to the context of the country. Yan et. al. (2011) also mentioned that emission factor can be presented as a mass-based (eg. Grams of pollutants per kilogram of fuel) or service-based emission factor (eg. grams of pollutant per kilometre driven). Usually the emission factor increases with the age of vehicle. He also summarizes the emission factor by using baseline emission factors for U.S. and European standards and by using the degradation rate for used vehicles. Averaged emission factors as $1.7 \mathrm{~g} / \mathrm{kg}$ fuel from data reported by EEA (2002) for Euro I, and as $1.3 \mathrm{~g} / \mathrm{kg}$ fuel for the US standard. Then, emissions increase linearly with a rate depending on technology during degradation phase. During the final years of vehicle service, emissions maintain a maximum level. $0.04 \mathrm{~g} \mathrm{~kg}$ _1-fuel/year for pre-baseline standards and $0.005 \mathrm{~g} \mathrm{~kg}$ _1-fuel/year for post-baseline standards could be considered as degradation rate. 
Figure 8 2002/03 imported used car vehicle stock at different time

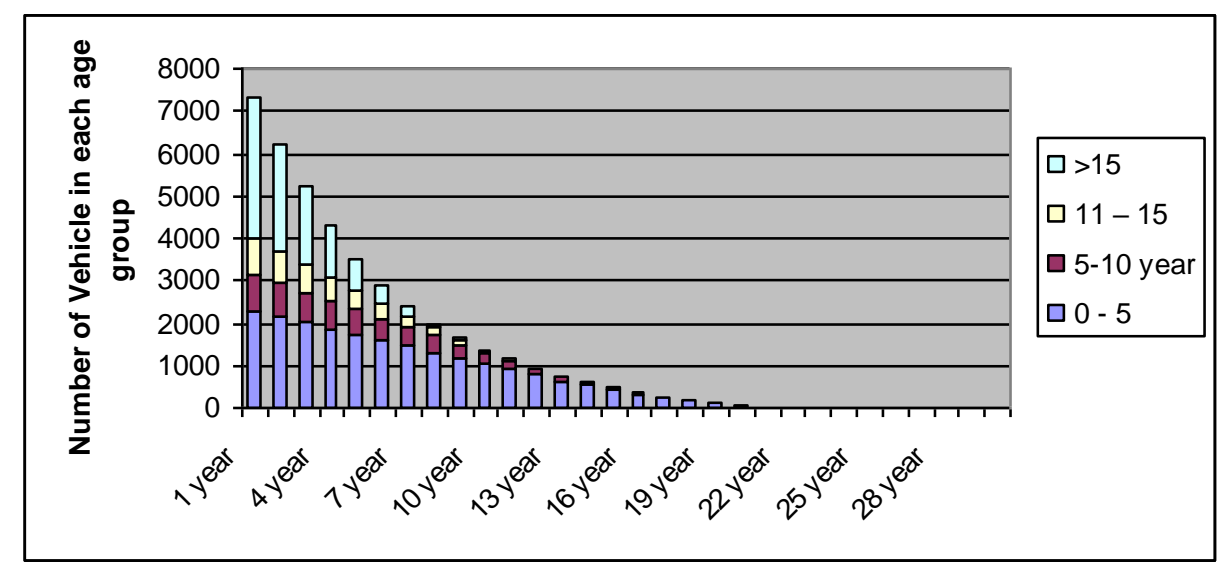

Figure 9 total used cars vehicle emission imported in 2002/03

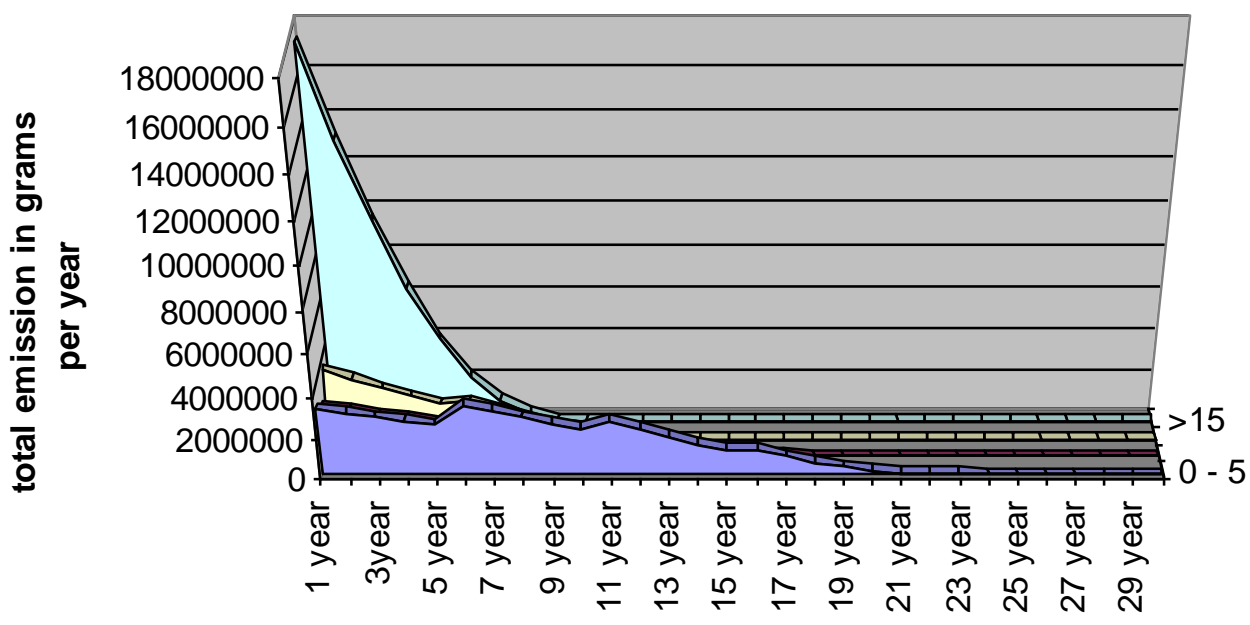

Therefore, based on the existing stock of vehicles and expectation of $10 \%$ annual importing of vehicles out of which $85 \%$ is used vehicle, and the survival rate described above, it is possible to calculate the emission based on the stock of vehicles

Hirota (2007) has also used cohort model to estimate the passenger car ownership that eventually used in the analysis of emission reduction. His analysis could help to understand and determine how much the share of vehicle control by vehicle regulation, such as environmental labelling of the vehicles. The model uses the concept of survival rate to estimate emission from car stocks.

However, this study used a time range of 0-5, 5-10, $10-15,>15$ years. And based on the above baseline emission factor and degradation rate, four emission factors are calculated to suit each time range and the total emission from the vehicles from 2002/03 to 2015 as shown in the Figure 9. Therefore, the following emission factors used to estimate the total emission; $1.3 \mathrm{~g} / \mathrm{Kg}, 1.7 \mathrm{~g} / \mathrm{kg}, 1.98 \mathrm{~g} / \mathrm{kg}$ and $2.1 \mathrm{~g} / \mathrm{kg}$ respectively to the time -range mentioned above. Besides the fuel efficiency also decreased through time and it is calculated as an average of $14 \mathrm{~km} / \mathrm{Kg}$,
$12 \mathrm{~km} / \mathrm{kg}, 10 \mathrm{~km} / \mathrm{kg}$ and $8 \mathrm{~km} / \mathrm{kg}$ respectively to the time range.

\section{CONCLUSION}

This paper has shown the relationships between vehicle survival rate, total emission, and fuel consumption. The result and analysis of estimation models entails that the older vehicles accounts for a large percentage of the total emission. Therefore, governments should introduce new regulatory policy instruments to inhibit the usage of less efficient imported used cars such as employing pre- 
shipment inspection, environmental policing, and introducing environmental based taxation systems. Understanding the vehicle survival rate and associated the total emission emitted in total lifetime is useful for policymakers to make a learned and informed decision to choose the right regulatory as well as economic mitigation instruments. Furthermore, to minimize outdoor pollution, the author also encourages facilitation for free taxation and other incentives to green transportation such as electric vehicles and scooters. Hence, government policy makers should look at long-term effects of transportation planning and management, especially in calculating cost benefit analysis for the incentive they provide to used car importation.

\section{REFERENCE}

[1] De Jong et. al, 2004, A comparison of car ownership models. Transport Reviews, 24 (4). Pp. 397-408. ISSN 1464-5327

[2] Briggs, David, 2003, Environmental pollution and the global burden of disease, British Medical Bulletin; 68: 1-24

[3] Feeney, Bernard P. 1988, Car longevity in Sweden: a revised estimate, Transportation Research A, 22A No 6, pp. 455-465

[4] M Wang, H. Huo, L.Johnson, D.He, 2006, Projection of Chinese Motor Vehicle Growth, Oil Demand, and CO2 Emission through 2050, Argonne National Laboratory

[5] Yan, fang; Winijul Ekbordin; Jung, Soonkyu; Bond Tami; Streets, David, 2011, Global emission projections of particulate matter (PM); I. Exhaust emission from on-road vehicles, atmospheric environment, doi: 10.1016/j.atmosenv.2011.06.018

[6] Hirota, Keiko, Policy for better air quality in Asia: proposal for a policy evaluation method for four ASEAN countries, studies in regional science. Vol.28 No 4, pp 1093-1104

[7] Hayashi, Yoshitsugu; Kato, Hirokazu; Teodoro, Rene; 2001, Journal of the Eastern Asia Society for Transportation Studies, Vol 4, No 5

[8] Greenspan, Alan; Cohen, Darrel, 1999, The Review of Economics and Statistics, 81(3); 369-383

[9] Walker, F. 1968, Determinant of Auto Scrappage" Rev. Econ. Statist, 50, 503-506

[10] Zachariadis, T., Samaras,Z., K.-H., 1995 Dynamic modeling of vehicle populations: an engineering approach for emission calculations. Technological Forecasting and Social Change 50, 135-149 